Doutorando em Semiótica no Instituto Italiano de Ciências Humanas (Universidade de Bolonha) e na Faculdade de Filosofia, Letras e Ciências Humanas (USP). Trabalha com Semiótica da Cultura e Sociossemiótica. 0 objeto de estudo de sua tese é a história do futebol brasileiro nas suas relações com o processo de construção da identidade dos estereótipos nacionais. E-mail: paolodemuru@gmail.com

\title{
Futebol brasileiro: o estilo, o jogo, a história
}

\section{Brazilian soccer:} the style, the game, the history

[resumo] Desde a Copa de 1938, o estilo brasileiro de futebol tem se tornado cada vez mais textualizado e estereotipado. Discursos jornalisticos, publicitários e até mesmo históricos e antropológicos contribuiram para naturalizar as performances brasileiras nos campos de futebol ou relacioná-las a algumas supostas habilidades corporais afro-brasileiras ou a outras práticas nacionais, como o samba e a capoeira. A tal ponto que, hoje, o jeito brasileiro de jogar futebol é uma forma explíita de vida cultural, que se reflete internacionalmente na imagem global do Brasil. 0 objetivo deste trabalho é apresentar uma perspectiva semiótica do seu processo de formação e discursivização. Mais especificamente, procuraremos descrever como é o resultado da interação entre as diferentes camadas glocais: 1. a ascensão e queda do futebol amador, jogado pelas elites de São Paulo e Rio de Janeiro e marcado pela aquisição de tendências e hábitos europeus; 2 . uma interpretação e aplicação local das regras do jogo, particularmente da regra do charge (tranco), que foi rigorosamente interpretada como uma falta (o que favoreceu o desenvolvimento de uma forma menos fisica de jogar); 3. a reconfiguração da tensão social e étnica - que permeou o Brasil após a abolição da escravatura - dentro (e fora) dos campos de futebol; e 4. a globalização discursiva - via futebol - de caracteristicas afro-brasileiras (como a ginga) em todo a cultura brasileira.

\section{estilo; futebol; ginga; história; semiótica.}

[abstract] Since the 1938 World Cup, the Brazilian way of soccer has increasingly become textualized and stereotyped. Journalistic, marketing, even historical and anthropological discourses all contributed to naturalize Brazilian performances on the soccer fields, either relating them to some assumed Afro-brazilian's "innate" bodily skills or to further Afrobrazilian bodily practices - such as samba or capoeira. All this was so intense that nowadays the Brazilian way of playing soccer is an explicit form of cultural life, which internationally reflects the global image of Brazil. The aim of this paper is to present a semiotic perspective on the process of formation and discoursivization of the Brazilian way of soccer. More specifically, we will seek to describe how is the result of the interplay among different glocal layers: 1. the rise and the fall of the amateur soccer, played by the elites of São Paulo and Rio de Janeiro and marked by the assumption of European trends and habits; 2. a local interpretation and application of the game rules, particularly the charge rule, which was strictly interpreted as a foul (favouring the development of a less physical way of playing); 3. the reconfiguration of the social and ethnic tension - that pervaded Brazil after the slavery abolition - inside (and then outside) the soccer fields; 4 . the discursive globalization - via soccer - of the Afro-brazilian characters (such as ginga) in the whole Brazilian culture.

[key words] style; soccer; ginga; history; semiotics. 


\section{0 estilo e a língua}

As astúcias do corpo são astúcias da palavra. Para não passar despercebido ao longo dos anos, o gesto atlético precisa de uma boa tradução. É o caso da "defesa do escorpião", do goleiro colombiano Higuita, ou da famosa "mão de Deus", de Diego Armando Maradona, lance um pouco menos atlético que o primeiro'.

Como dizia o diretor italiano Nanni Moretti, "as palavras são importantes"2. Se isso é verdade, escrever uma pequena semiótica (cultural) do futebol brasileiro nos convida, antes de mais nada, a refletir sobre os modos de dizer e definir, e nos obriga, de certo modo, a avaliar seu peso e a traçar seus destinos - ainda mais se as suas consequências repercutem para além do âmbito futebolístico, alcançando profundamente as estruturas do pertencimento nacional.

Dar nomes é coisa boa e útil. Jogadores e cronistas brasileiros parecem ser bem conscientes dessa necessidade semiótica. A prova disso é a proliferação das descrições e definições de dribles e jogadas - "bicicleta", "passe de letra", "drible da vaca", "chapéu", "elástico", "foca", "pedalada", para citar alguns - ou, ainda, a invasão dos dicionários de futebol, que hoje observamos nas prateleiras das livrarias de São Paulo e Rio de Janeiro.

Se existe um termo que resuma a força e relevância de certas figuras do corpo, ligadas à prática futebolística, no processo de construção da memória e da identidade cultural brasileira, este é sem dúvida "ginga". Da capoeira, ao samba, ao futebol, à vida: ginga é um verdadeiro vocábulo migratório, através do qual e sobre o qual foram construidos significados sociais e caracteres coletivos.

Para compreender realmente a evolução semântica e resumir sua trajetória, propomos aqui comparar brevemente duas definições retiradas de dois importantes depósitos do senso comum: o Dicionário Houaiss da Língua Portuguesa e o comercial da Brahma, famosa cerveja que sempre promoveu os valores da "brasilidade" (OLIVEIRA e LANDOWSKI, 2002).

Segundo o Dicionário Houaiss, "ginga" significa: "1. ato ou efeito de gingar; meneio de corpo, trejeito; 2. movimento com que o capoeirista procura enganar e desnortear o adversário, tanto para defender-se como para atacar; 3. no futebol, série de movimentos do corpo que visam enganar o oponente". Derivado do substantivo, o verbo "gingar", por sua vez, é definido do seguinte modo: "1. curvar(-se) [corpo ou membro] para um e outro lado, esp. ao andar; bambolear(-se); 2 . menear os quadris; requebrar-se, rebolar; 3 . agitar-se, balançar-se; 4. (fig.) negar-se com desdém a atender um pedido; 5. no futebol, fazer gingas".

0 dicionário registra a presença de um único sentido figurado: "negar-se com desdém a atender um pedido". De resto, com uma leitura ingênua, já se percebe que a ginga é um movimento do corpo centrado nos 


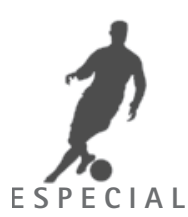

quadris, praticado no caminhar cotidiano, na capoeira e no futebol. Uma espécie de inteligência ou malícia corpórea.

Assim como o dicionário, a campanha publicitária internacional Brahma brings ginga to our consumers - veiculada em 2008, em ocasião do lançamento da cerveja Brahma no mercado global - acentua e reforça esse "saber fazer" sensivel. Ali também se diz, de fato, que a ginga é "o jeito como os brasileiros andam, se mexem, a forma como jogam futebol". Aparentemente nada de novo. No entanto, a propaganda nos mostra algo a mais: "o jeito que os brasileiros andam e se mexem". Não se trata, portanto, de um movimento estereotipado, sujeito a ser reproduzido individualmente, mas sim de uma qualidade coletiva, da postura de um povo. E continua o anúncio: "a Brahma oferece o gosto da cultura brasileira, uma cultura em que as pessoas encaram a vida com um brilho e sem esforço ou, como dizem os brasileiros, com ginga (...) ginga é uma atitude e um estilo de vida com base numa visão de vida otimista e criativa". 0 termo adquire um valor que vai além do significado puramente "cinésico" do gesto. Ademais, a ginga já não é apenas um "modo de mover o corpo", mas um modo de comportar-se, uma disposição, um estilo nacional.

Deveriamos então nos perguntar: como chegamos a tal afirmação? Qual é o ponto convergente entre o dicionário e a cerveja Brahma? Como a ginga migra da capoeira ao futebol até a vida? Como e por que uma expressão, antes confinada unicamente à memória afro-brasileira, é hoje "símbolo" e "dispositivo estereotipante" (LOTMAN e USPENSKIJ, 1975, p. 42) de toda uma nação?

Certamente as palavras desempenharam nesse processo um papel determinante. Não é por acaso que, com o passar do tempo, os sinônimos de ginga tenham cada vez mais se multiplicado, até chegarem hoje a constituir uma constelação de significações que orbitam em torno do termo. Da mesma forma, não é casual o fato de uma cultura chamar o seu estilo de jogar futebol de "futebol arte", independentemente do fato de isso "existir" ou não - discussão que é melhor deixar aos jornalistas e comentaristas esportivos. A nós basta saber que é possivel encontrar alguma tradução. Afinal, no futebol, assim como na história, lutar pela memória significa lutar contra o indizível.

\section{0 estilo e a história}

Ainda garoto eu tinha medo de jogar futebol, porque vi muitas vezes jogador negro, lá em Bangu, apanhar em campo só porque fazia uma falta, nem isso às vezes. (...) Meu irmão mais velho me dizia: "malandro é o gato, que sempre cai de pé. (...) Tu não é bom de baile?" Eu era bom de baile mesmo e isso me ajudou em campo. (...) Eu gingava muito. (...) 0 tal do drible curto eu inventei imitando o "miudinho", aquele tipo de samba. (MURAD, 2007, p. 27)

Essas palavras são de Domingos da Guia, jogador da seleção brasileira que disputou a Copa do Mundo de 1938 na França. Compreender tal afirmação significa entender, de um lado, como a ginga surgiu nos campos de futebol e, de outro, como e por que certas qualidades dos jogadores afro-brasileiros (primeiro) e brasileiros (depois) tenham sido, ao longo do século $X X$, naturalizadas, estereotipadas e convertidas em símbolos nacionais.

Ao contrário do que aconteceu na Inglaterra, onde a prática do futebol sofreu um processo de massificação muito mais rápido e indolor, no Brasil os campos de futebol foram palco, ao menos até os anos 1930 e 1940, de um grande conflito sociocultural. 
Crescido nos últimos anos do século XIX no seio da elite paulistana e carioca, o futebol se transformou rapidamente, a partir do início do século $X X$, em um verdadeiro símbolo de distinção social. A esse propósito, basta lembrar que, em 1905 e 1906, o Botafogo importava o próprio uniforme da Inglaterra, enquanto 0 Fluminense, por uma razão puramente estética, jogava com um finissimo cinto vermelho. As partidas terminavam, na maioria das vezes, em festas. Os jogadores degustavam cigarros e uísques importados, e era absolutamente proibido ofender os jogadores da equipe adversária (PEREIRA, 2000). 0 bom jogador tomava chá às cinco em ponto - o five o'clock, como se dizia -, fazia a barba no Salão Naval do Rio, jantava na rotisserie. Jogar futebol era uma prática dentro de um universo de práticas no qual se traduziam e se reproduziam os valores da aristocracia europeia. Fora desse universo, a prática era absolutamente privada de sentido.

Para entender a peculiaridade desse processo, basta contemplar os primeiros manuais de futebol publicados no Brasil. No Guia de football, do jornalista Mario Cardim, que traduz para o português pela primeira vez, em 1906, as regras da International Football Association Board (iFAB), é possivel encontrar, por exemplo, um pequeno texto intitulado: "As qualidades físicas e morais dos jogadores de football", que, junto com as descrições das principais artimanhas do jogo, elencava uma série de etiquetas comportamentais que deveriam ser respeitadas dentro e fora do campo. Esses textos ofereciam um verdadeiro e próprio "modelo de mundo" ao praticante da época, contribuindo, da mesma forma, para a formação de um ethos específico do sportman, visto como homem de bons princípios, de boas maneiras e de boas atitudes.

Ao mesmo tempo, o novo esporte começava a fazer muito sucesso nas fábricas e nas periferias urbanas. Recém-saído da escravidão, o país enfrentava naqueles anos um período de grande migração. Famílias de ex-escravos se dirigiam às grandes cidades em busca de casa e trabalho, ocupando terras em morros próximos ao Centro e em outras regiões de difícil acesso. Nasceram então as primeiras favelas e algumas equipes, como o Bangu de Domingos da Guia, que começaram a colocar em campo operários, em sua grande maioria negros e mulatos.

Como é possivel imaginar, esse movimento de expansão e massificação da prática esportiva não foi visto com bons olhos pelos promovedores tropicais do esporte britânico. Iniciou-se, então, a proibição do acesso de analfabetos e braçais aos clubes, a exigência de valores exorbitantes para o pagamento das taxas de inscrição dos jogadores nos campeonatos municipais e, enfim, como aparece no estatuto da Liga Metropolitana do Rio de Janeiro, a proibição da presença em campo de "pessoas de cor".

No entanto, ocorrem, nesse momento, duas coisas bastante interessantes, que concernem diretamente ao problema da tradução desse conflito sociocultural no campo de jogo. 
A primeira tem a ver com as regras da iFAB e, em particular, com a regra 9, que disciplinava o charge, "tranco" em português. Diferentemente de outras nações nas quais essa regra passava quase despercebida, no Brasil ela se transformava em uma verdadeira "questão pessoal", assumindo um papel de importância capital para o futuro do jogo. É aqui que se repete o esquema da distinção social. Leiamos a definição do manual de Cardim (1906, p. 40): "a charge é permitida mas não de modo violento ou perigoso". Sentença sucinta, mas de resultados nada óbvios. É claro que hoje, como naquele tempo, todo o dilema está naquele "mas não de modo violento ou perigoso". 0 problema é genuinamente semiótico: trata-se de uma questão de interpretação, ou melhor, de negociação do significado. Em outras palavras, é possível concordar facilmente com o fato de que o tranco não deve ser violento ou perigoso, mas entrar em acordo quanto ao "que" seria ou não violento e perigoso não é uma tarefa simples. Ao contrário, é uma prática competitiva, ainda mais dentro de um campo de futebol. E se o termo é vago, passam a valer, então, as relações de força. Não as interpretações em estilo "jornalístico", mas a autoridade de quem estabelece sensos e consensos - que, naquele tempo, certamente não era representada pela figura do árbitro. Possuidores de autoridade, os sportmen da elite souberam aproveitar bem o benefício da dúvida admitida no texto. Se o "que" e o "como" representavam uma incógnita, mais fácil, então, definir o "quem". "Quem" era violento e perigoso? A resposta para essa pergunta parecia bastante óbvia: violentos e perigosos eram os negros, mulatos, mestiços, operários, analfabetos. Como escreveu Umberto Eco (1984, p. 241) , "possuir a chave da interpretação, isso é o poder".

A segunda questão - consequência direta da primeira - nos remete às declarações de Domingos da Guia. Porque os negros e mulatos que tocassem o adversário branco estavam sujeitos a punições que iam muito além da advertência ou da expulsão da partida. Qualquer negro ou mulato que cometesse uma suposta falta ou uma hipotética infração no contato corpo a corpo era literalmente espancado. Agredido, às vezes, até pela polícia, como relatam outras testemunhas. É fácil imaginar que um rapaz negro da periferia do Rio de Janeiro tivesse medo de jogar bola.

Resumindo, o quadro aqui apresentado está composto do seguinte modo: 1. uma série de "normas morais" que proibiam ou desaconselhavam a convivência entre homens de diferentes classes e diferentes "cores"; 2 . uma regra "global" que, para se adaptar a tais hierarquias "locais", é interpretada em sentido, assim dizendo, muito "estreito"; e 3. agressões físicas contra suspeitos de subverter a ordem do jogo - que é também um modelo reduzido da ordem social. Em outras palavras, a distância que existia na sociedade se traduzia no campo em uma recusa ao contato físico.

Tal princípio de estigmatização do "tocar" e do "tocar-se" se estabilizou com o passar do tempo, chegando até a criar problemas nas competições internacionais. A esse respeito, podemos citar Ademir Pimenta, treinador da seleção de 1938, na qual Domingos da Guia era titular, que considerava o jogo de corpo um dos principais problemas da seleção diante das equipes europeias, acostumadas a jogar de um modo muito mais duro (TOLEDO, 2002).

Tudo isso nos ajuda a desvendar como funcionam certos mecanismos da tradução cultural e a compreender como os significados - inclusive aqueles de aparência mais resistente, como os normativos - sejam sempre localmente definidos e redefinidos. Não se trata de processos de liquidificação do sentido, mas de dinâmicas complexas, nas quais os jogos de poder têm muita importância.

Não apenas isso. Há ainda mais, e aqui retornamos à questão do corpo. A história da interpretação das regras - assim como a história de Domingos - nos permite apresentar uma hipótese sobre a origem do "estilo brasileiro de jogar futebol" ou, se preferimos, de discutir abertamente a suposta naturalidade da "ginga". Lembremos agora da cerveja Brahma: "o jeito como os brasileiros andam, se mexem, a forma como jogam futebol". Isso é verdade, como afirma o próprio jogador: "eu gingava muito, o tal do drible curto eu inventei imitando o 'miudinho', aquele tipo de samba". No entanto, é ele também a dizer que os jogadores negros apanhavam unicamente pelo fato de terem cometido uma falta, quando a falta, às vezes, nem sequer existia. Não é, portanto, imprudente supor que o gosto pelo drible, pela improvisação, pela manha, criado dentro desse sistema de normas e prescrições, tenha nascido não de uma característica ou atitude hereditária do corpo afro-brasileiro, mas sim da necessidade 
de se evitar o contato. Que depois surjam histórias a esse respeito, com um jogo de palavras poderiamos dizer que essa é uma outra história.

\section{Narrações do estilo}

Em 1938, durante a Copa do Mundo francesa, Gilberto Freyre publica um artigo no Diório de Pernambuco intitulado "Football Mulato". Trata-se de uma verdadeira "mitologia" do estilo brasileiro de jogar futebol. Aliás é, de certo modo, a sua certidão de nascimento. Se é verdade - e hoje em dia, óbvio - que nos definimos unicamente na relação com a alteridade, qual ocasião melhor que uma competição mundial para refletir sobre aquilo que se é ou não é? Imerso em uma prosa de tons líricos e visionários, o autor desenha uma trama de relações e oposições internas e externas à cultura brasileira, por meio da qual define modos de ser e estar no mundo: dionisíaco, apolíneo, macio e áspero, espontâneo e artificial, democrático e autoritário, virtuosismo individual e técnica cientifica. Um dissolver de adjetivos, uma tela de contrários na qual o discurso sobre a identidade acaba aprisionado. Freyre realiza, em primeiro lugar, um elogio ao afro-brasileiro, enaltecendo a decisão de mandar uma equipe mestiça à Europa e comparando a tarefa da seleção ao estilo político de Nilo Peçanha, mulato de origem humilde que foi presidente da República e ministro das Relações Exteriores. Da política, passa, então, à dança, tecendo paralelos entre o drible dos jogadores afro-brasileiros e a elegância das bailarinas.

Neste momento, o leitor mais atento já terá notado como, em poucas linhas, foram colocadas sobre o mesmo plano três distintas esferas culturais: futebol, política e dança. Mas é justamente aqui que está o mais interessante. Colocando-a sobre um pano de fundo cromático - no qual o Brasil se contrapõe ao albinismo europeu -, 0 sociólogo decreta de fato a sua sentença final: "psicologicamente, ser brasileiro é ser mulato". Aqui está definido em poucas páginas o ethos e a estrutura profunda da brasilidade. Tudo com uma desenvoltura digna de um Garrincha de 1958 ou de um Pelé de 1970. E que nos perdoem a comparação.

Após Gilberto Freyre, o discurso do futebol no Brasil assumiu um papel de primeiro plano no processo de construção da identidade nacional. Jornalistas, historiadores, antropólogos, letrados e políticos aludiram a esse tema. 0 desenvolvimento desse percurso é complexo e, certamente, não é este o melhor lugar para discuti-lo. Isso que acabamos de propor é apenas um esboço. No entanto, vale a pena evidenciar o fato de o estilo ser magistralmente naturalizado; joga-se deste modo porque assim se move e se dança - quando, na realidade, como vimos, as coisas são bem mais complexas e complicadas. Enfim, a necessidade de relação entre o evento e a sua própria narração. Dito de um outro modo, o imprevisivel faz sentido somente quando é narrado. Tornar-se uma forma duradoura é uma questão de boa expressão. Para concluir: as histórias, assim como os corpos, são formas que permanecem. 


\section{NOTAS}

[1] Conforme artigo de Franciscu Sedda nesta edição de dObra[s].

${ }^{[2]}$ Numa cena do filme Palombella Rossa de 1989, Michele, o alter ego de Nanni Moretti (cineasta, ator e roteirista cinematográfico italiano) responde uma entrevista a uma jornalista e em determinado momento diz: "quem fala mal, pensa mal. E preciso encontrar as palavras adequadas: as palavras são importantes". N.E.

\section{REFERÊNCIAS}

CARDIM, Mario. Guia de football. São Paulo: Casa Vanordem, 1906.

ECO, Umberto. Semiotica e filosofia del linguaggio. Turim: Einaudi, 1984.

LOTMAN, Jurij M.; USPENSKIJ, Boris A. Sul meccanismo semiotico della cultura. In: della cultura. Milão: Bompiani, 1975. Tipologia

MURAD, Mauricio. A violência e o futebol: dos estudos clássicos aos dias de hoje. Rio de Janeiro: FGV, 2007.

OLIVEIRA, Ana Claudia de; LANDOWSKI, Eric. Entre o social e o estésico: análise de campanhas publicitárias de cerveja. In: VIII Caderno de discussão do Centro de Pesquisas Sociossemióticas. São Paulo: CPS, 2002, p. 415-444.

PEREIRA, Leonardo Affonso de Miranda. Footballmania: uma história social do futebol no Rio de Janeiro (1902-1938). Rio de Janeiro: Nova Fronteira, 2000.

TOLEDO, Luiz Henrique de. Lógicas no futebol. São Paulo: Hucitec/Fapesp, 2002. 